\title{
Role of slow breathing exercise on lung function status in depressive illness patients
}

\author{
KN Afreen ${ }^{1}$, NMW Rahman², S Ainan ${ }^{3}$, M Ferdous $^{4}$, S Fahmi ${ }^{5}$, M Akter ${ }^{6}$
}

\begin{abstract}
Major depressive disorder (MDD) is associated with depressed lung function. This depressed lung function can be improved by slow breathing exercise ((SBE). To observe peak expiratory flow rate (PEFR) in newly diagnosed MDD patients and after three months of regular practice of SBE. This prospective study was carried out in the Department of Physiology, Bangabandhu Sheikh Mujib Medical University (BSMMU) from January to December, 2014 to assess the lung function status in MDD patients. For this, 30 newly diagnosed MDD patients, aged 20 to 50 years were enrolled from the Department of Psychiatry of BSMMU. PEFR of all subjects were assessed by a portable digital spirometer before and after three months of regular practice of SBE. There was significant improvement of lung function status found when compared PEFR between before and after three months of regular practicing of SBE. From this study it may be concluded that SBE is very effective and potent method for improvement of poor lung function associated with all types of pulmonary functional disorder in MDD.
\end{abstract}

Key words: Major depressive disorder, slow breathing exercise, peak expiratory flow rate, lung function.

\section{Introduction}

Depression is the most common chronic condition next to hypertension experience in general medical practice. Out of ten patients visiting psychiatric outpatient department; one patient is suffering from major depression.

Major depressive disorder (MDD) is defined by depressed mood or loss of interest in nearly all activities or both for at least two weeks, accompanied by a minimum of three or four of the following symptoms (for a total of at least five symptoms altogether) such as insomnia or hypersomnia, feeling of worthlessness or excessive guilt, fatigue or loss of energy, diminished ability to think or concentrate, substantial change in appetite or weight, psychomotor agitation or retardation and recurrent thoughts of death or suicide. ${ }^{1}$

Depression is a major cause of morbidity worldwide. The World Health Organization ranks depression as the fourth leading cause of disability worldwide and by 2020 , it will be the second leading cause. Population stud-

\footnotetext{
1. KN Afreen, Assistant Professor of Physiology, ZH Sikder Women's Medical College Hospital, Dhaka. Email: drnadiaafreen@yahoo.com

2. NMW Rahman, Associate Professor of Microbiology, Gazi Medical College, Khulna

3. S Ainan, Assistant Professor of Physiology, Enam Medical College, Savar

4. M Ferdous, Assistant Professor of Physiology, Nightingale Medical College, Ashulia, Dhaka

5. S Fahmi, Assistant Professor of Biochemistry, ZH Sikder Women's Medical College, Dhaka

6. M Akter, Assistant Professor of Anatomy, ZH Sikder Women's Medical College, Dhaka
} 
ies have consistently shown major depression is about twice as common in women than in men, although the underlying cause and factor is unclear. Elderly people are more affected. People are most likely to suffer their first depressive episode at about 25.7 years in high income and 24 years in low to middle income country. ${ }^{2}$

Depression may affect all the organs of the body and is responsible for different diseases such as myocardial infarction, other coronary artery diseases, stroke, diabetes, kidney diseases, arthritis, Parkinson's disease and other autoimmune diseases. ${ }^{3}$ Researchers found depressed lung function in depressive illness patients which is more in MDD. ${ }^{4}$ Another study found that MDD was associated with lower FEV1. ${ }^{5}$ Whereas no difference in lung function was found in MDD patients when compared to control. ${ }^{6}$ Chanavirut and his colleagues investigated the effect of breathing and chest wall expansion exercise (yoga) on lung function parameters in young healthy volunteers. They found significant increase in FVC, FEV1, FEV25-75\% after practicing breathing exercise for 6 weeks. ${ }^{7}$ Sayyad and his colleagues studied lung function parameters on asthma patients after practicing eight weeks of yoga. They found significant increase in FVC and FEV1. ${ }^{8}$

In 2010, Ahmed and his coworkers studied lung functions in healthy volunteers who were exposed to yoga practice by employing posture and controlled breathing exercise (pranayam) for 30 days and 60 days in two age groups. They found significant increase in all spirometric parameters in all age groups after 60 days but these values were found increased in old age groups after 30 days. ${ }^{9}$ Another study found that after practicing yoga breathing exercise for 4 weeks, all the lung function parameters were significantly increased. ${ }^{10-12}$

Though there is accumulation of evidence in favor of improvement of lung functions in healthy adults but the effect of slow breathing exercise (SBE) as a part of yoga on lung function status in depressed patients so far has not been studied. The ultimate aim of this study is to find out whether this physiological intervention can bring benefit to the MDD patients protecting them from pulmonary dysfunction related complications.
Materials and Methods

This interventional study was carried out in the Department of Physiology, BSMMU, Dhaka, between January to December 2014. Thirty female newly diagnosed MDD patients aged 20 to 50 years constituted study group. Study protocol was approved by Institutional Review Board (IRB) of BSMMU, Shahabag, Dhaka. Patients were randomly selected from the outpatient department of the Department of Psychiatry of BSMMU, Dhaka. Subjects with pregnancy and lactation and history of lung diseases, coronary heart disease, diabetes mellitus, neurological disorders, smokers were excluded from the study. After selection when they agreed to participate, an informed written consent was taken from each subject. A detail personal, medical, family, socioeconomic, occupational and drug history were recorded in a preformed questionnaire and through physical examinations were done and documented. Then the benefit of SBE and its useful effect on lung function as well as depression itself explained to the patient and also to their accompanying relatives. In addition, the steps of SBE in detail, the time period and environment of practice was taught. Special emphasis was given to ensure the regular practice of this exercise by the patients. For this, relatives were adequately informed to monitor and ensure it. The subjects were regularly contacted and monitored through telephone and occasionally by visiting home. They were also asked questions to make sure whether the exercise was practiced correctly.

For this assessment of lung function peak expiratory flow rate (PEFR) of all the subjects were recorded by a digital spirometer (PONY FX, Cosmed, Italy) before and after three months of anti-depressive medication or SBE practice. Data were expressed as mean \pm SE (Standard Error). Paired sample t-test was done to compare between the groups by using SPSS (Windows version 16). In the interpretation of results, $p<0.05$ was accepted as level of significance.

\section{Results}

There was no significant change found in patients taking antidepressive medication when compared between before and after three months of medication.

Table 1 shows the frequency distribution of 
Table 1. Frequency distribution of $\mathbf{3 0}$ female newly diagnosed major depressive disorder patients

\begin{tabular}{lrr}
\hline Characteristics & N & $\%$ \\
\hline Level of education & 13 & 44 \\
Primary school & 10 & 33 \\
Junior high school & 3 & 10 \\
High school & 4 & 13 \\
Degree and above & & \\
Occupation & 7 & 23 \\
Employed & 23 & 77 \\
Unemployed & & \\
Religion & 30 & 100 \\
Muslim & & \\
\hline
\end{tabular}

Table 2. Baseline characteristics of $\mathbf{3 0}$ female newly diagnosed major depressive disorder (MDD) patients

\begin{tabular}{lcccc}
\hline & $\begin{array}{c}\text { Age } \\
\text { years } \\
\text { (range) }\end{array}$ & $\begin{array}{c}\mathrm{BMI} \\
\mathrm{Kg} / \mathrm{m}^{2} \\
(\text { range) }\end{array}$ & $\begin{array}{c}\mathrm{SBP} \\
\mathrm{mmHg} \\
\text { (range) }\end{array}$ & $\begin{array}{c}\mathrm{DBP} \\
\mathrm{mmHg} \\
\text { (range) }\end{array}$ \\
\hline MDD patients & $34.1 \pm 1.5$ & $27.5 \pm 0.6$ & $120 \pm 1.9$ & $79 \pm 1.7$ \\
& $(22-50)$ & $(20.2-32.2)$ & $(100-140)$ & $(60-90)$ \\
\hline
\end{tabular}

Data were expressed as mean \pm SE. Figures in parentheses indicate range. BMI, body mass index; SBP, systolic blood pressure; DBP, diastolic blood pressure.

Table 3. Percentage of predicted values ofpeak expiratory flow rate (PEFR) in different groups

\begin{tabular}{lrc}
\hline Parameters & MDD newly & MDD after three \\
& months of SBE \\
\hline PEFR & $35.05 \pm 4.67$ & $53.43 \pm 4.04^{\star \star \star}$ \\
& $(9-89)$ & $(28-111)$ \\
\hline
\end{tabular}

$\mathrm{MDD}$, diagnosed major depressive disorder. Data were expressed as mean \pm SE. Figures in parenthesis indicate range. ${ }^{* * *}: p<0.001$ by paired $t$-test.

30 female newly diagnosed MDD patients. Table 2 shows the baseline characteristics of them. Percentage of predicted values of PEFR in different groups are presented in Table 3. The PEFR in MDD after three months of SBE was significantly higher than in MDD newly diagnosed $(p<0.001)$.

\section{Discussion}

The present study was conducted to observe pulmonary functions in 30 female MDD patients before and after three months of practicing an yoga based relaxation technique, SBE. Pulmonary functions were assessed by measuring PEFR with a portable micro spirometer. Different researchers found that pulmonary functions are significantly reduced in patients with depressive illness especially in MDD patients. Islam and his colleagues investigated lung function by spirometry in depressive disorder patients and found lung function parameters were significantly lower in depressive disorder patients in comparison to healthy subjects. ${ }^{4}$ Another study was done on US soldiers with Vietnam experience to find out association between MDD with lung function. But they did not found any significant association between MDD and poor lung function. ${ }^{5}$ Calikoglu and his colleagues 
investigated lung function test by spirometry in $\mathbf{3 0}$ female MDD patients. After comparing with control group, they found that dyspnea was higher in MDD. In this study, PEFR in newly diagnosed MDD patients were significantly lower than those of apparently healthy subjects. ${ }^{6}$ The apparent effect of depression on poor lung function in MDD patients may be explained by the reduced psychomotor activity along with poor respiratory muscle strength in depressive illness. ${ }^{13}$ It is surprisingly noted that in MDD patients after 3 months of SBE (Anulom-Vilom Pranayama) beside medicine, overall lung function was significantly improved, evidenced by the significantly higher values of all spirometric indices. The benefit of SBE for improvement of respiratory efficiency is derived from multiple factors. One of the suggested cause for improvement of respiratory efficiency by SBE is, its deep inhalation and prolonged expiration cause efficient use of diaphragm and abdominal muscle and intercostals muscle which ultimately improves the strength of this respiratory muscles. In addition, the stress on more prolonged expiration deep inspiration trains the respiratory apparatus for more efficient and complete emptying and filling of airways.

The poor strength for spirometric performance due to poor muscular strength due to depression is thus overcome by the increased strength of respiratory muscle achieved by SBE. In SBE procedure, deep breathing at slow phase reduces dead space and increased alveolar ventilation. Consequently, this increases vital capacity. The significant improvement of PEFR after practicing SBE for 3 months provides the evidence of improved ventilator function of lung. ${ }^{14}$ During SBE, the thoracic and lung compliance increases, airway resistance decreases which is supporting the increased value of FEV1, FEV1/FVC ratio in MDD patients in the present series. ${ }^{15}$

\section{Conclusion}

Therefore finally it can be concluded that SBE is a very effective and potent method for improvement of poor lung function associated with all types of pulmonary functional disorder in MDD. Thus SBE can be strongly advocated as an alternative or adjunct to antidepressive medication in the MDD for improvement of their respiratory efficiency.

\section{References}

1. Whooley MA, Simon GE. Managing depression in medical science. $\mathrm{N}$ Engl J Med 2000;343:1942-50.

2. Bromet E, Andrade LH, Hwang I, et al. Cross national epidemiology of DSM IV major depressive episode. BMC Medicine 2011;9:90.

3. Aminpoor $\mathrm{H}$, Afshinfar J, Mostafaei A, Ostovar S. Validation of Goldberg's Depression Scale in academic and non-academic people. Ann Biol Res 2012;3(9):4564-73.

4. Islam S, Jahan N, Sultana N, Akhter R. FVC, FEV1 and FEV1/FVC\% in patients with depressive illness and their relationships with the level of depression. J Bangladesh Soc Physiol 2010;5(2):94-100.

5. Carroll D, Phillips AC, Gale CR, Batty GD. Generalized anxiety disorder is associated with reduced lung function in the Vietnam experience study. Psychosom Med 2011;73:716-20.

6. Calikoglu M, Sahin G, Yazici AE, Yazici K, Ozisik S. Pulmonary muscle strength, pulmonary function tests and dyspnea in women with major depression. J Women Health 2004;13(1):1-7.

7. Chanavirut $R$, Jaree $P$, Pongnavatorn $P$. Yoga exercise increases chest wall expansion and lung volume in young healthy Thais. Thai J Physiol Sci 2006;19(1):1-7.

8. Sayyad R, Yadav K, Sah S, Kar K. Evaluation of pulmonary function test before and after yoga practice in asthma patients. Indian J Basic Appl Medl Res 2014;3(3):8-14.

9. Ahmed QR, Sau SK, Kars SK. An evaluation of pulmonary parameters in two groups of subjects during yoga practice. Nepal Med Coll 2010;12 (3):180-2.

10. Sodhi C, Singh S, Dandona PK. A study of the effect of the yoga training on pulmonary function in patients with bronchial asthma. J Physiol Pharmacol 2013;53(2):169-74.

11. Panwar S, Chovrishi A, Makwana J. Effect of pranayama on pulmonary function test of young healthy students. Int $J$ Pharm Bio Sci 2012;3(4):12-6. 
12. Yadav RK, Das S. Effect of yogic practice on pulmonary function in young females. Indian J Physiol Pharmacol 2001; 45(4):493-6.

13. Kupfer DJ, Weiss BL, Foster FG, et al. Psychomotor activity in affective states. Arch Gen Psy 1974;30(6):765-8.
14. Sivapriya DV, Suba MS, Thirumenis E. Effect of Nadi Shodhana Pranayama on Respiratory parameters in school students. ISSN 2010;2(11):32-9.

15. Panwar S, Chovrishi A, Makwana J. Effect of pranayama on pulmonary function test of young healthy students. Int $\mathrm{J}$ Pharm Bio Sci 2012;3(4):12-6.

\section{Suggestion for citation of the above:}

Afreen KN, Rahman NMW, Ainan S, Ferdous M, Fahmi S, Akter M. Role of slow breathing exercise on lung function status in depressive illness patients. Mediscope 2016;3(2):26-30. 